\title{
Abstracts of Technical Papers, Annual Meeting, Canadian Institute of Forestry St.John's, Newfoundland September,
} \section{8}

The Forestry Picture Now and Forty Years Hence. As seen by an Economist

by D. P. Drysdale,

Department of Lands and Forests,

Toronto, Ontario.

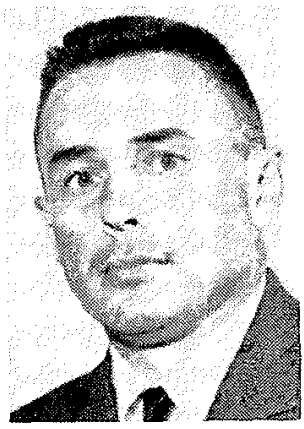

The forest industries are Canada's most important manufacturing group. They account directiy for about $14 \%$ of the number of persons employed; the salaries and wages paid; and the amount of capital invested. A rosy outlook is forecast for at least the next 10 years with a continuing high demand likely throughout the next 40 years. According to estimates it would appear that the demand for wood will exceed the present annual supply about 1990.

The increased demand for wood products which is forecast does not automatically guarantee that Canada will continue to play a leading role in supplying world needs indefinitely. A number of problems facing our industries are discussed including the need for modern manufacturing establishments in some localities, increasing productivity, and decreasing costs. Studies to determine the total economic impact of Canada's forest industries are called for as well as trend studies to provide guidance as to the best course for future development. Foresters are challenged to ensure that adequate supplies of wood will be available to meet the increased demand.
The Forestry Picture Now and Forty Years Hence

by D. T. Seal,

Forestry Commission

Research Branch Edinburgh, Scotlond

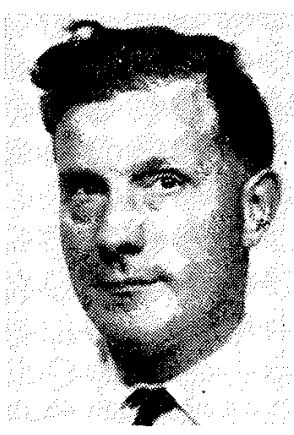

The forestry picture in Britain now has something in common with that in many other countries. British forestry is founded mainly upon exotic species, especially from North America and has been strongly influenced by developments in Europe and elsewhere.

In Britain, tree performance has been greatly improved by selection of species and provenance but potential production is far from being realized as yet. Further improvements are expected from tree breeding, and cultivation and nutrition combined with detailed examination of forest soils are rapidly developing fields.

Windthrow is a recurrent problem - it cannot be prevented but progress is being made towards reducing damage. Research into regeneration of even-aged crops is starting to yield results.

Developments in the short term are easy to foresee but developments over the next 40 years will depend upon many variables some of them outside forestry. 
Future Requirements Reforestation and Afforestation. The Viewpoint of Industry

by B. R. Pryde,

Bowaters Newfoundland Ltd. Corner Brook, Newfoundland

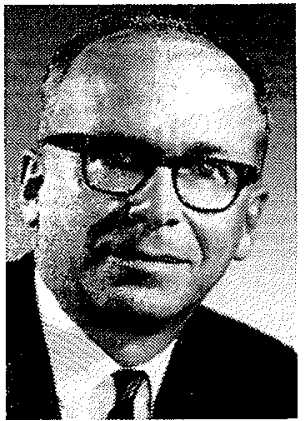

The maintenance of productivity and the increase in the fibre producing capacity of company limits are prerequisites to the continued operation of mills in the pulp and paper industry. New mills and increased output will produce increased future wood fibre requirements which will only be satisfied by keeping all productive or potentially productive areas in full production.

A number of problems have arisen in the management of black spruce and balsam fir, the primary species utilized by the Newfoundland pulp and paper industry. These problems include delays or failures of regeneration, the establishment of dense balsam fir stands on sites that previously carried black spruce, and the long term effects of fires on forest growth.

Restocking programs should be a joint undertaking between industry and government, with the latter taking the leadership. Large-scale programs should be initiated as soon as possible if we are to make a dent in the total reforestation problem in Newfoundland. Very little is yet known about the afforestation of peatlands and research must be completed before the possibilities of using peatlands for forestry purposes can be properly determined.

The attainment of better levels of stocking and an increase in production through fertilization are seen as means by which the present high costs of harvesting pulpwood might be reduced.

Future Requirements in Reforestation and Afforestation. The Viewpoint of Industry

by D. I. Crossley,

North Western Pulp

\& Power Ltd.

Hinton, Alberta

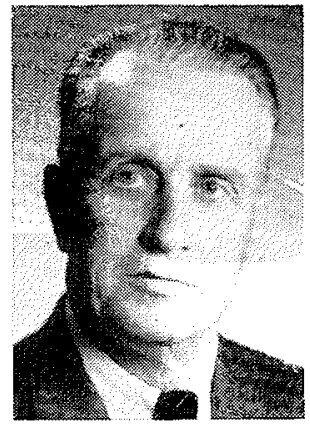

How does the current nation-wide program of reforestation equate with the job needing to be done? A huge back-log of non-regenerated cutovers, the failure to keep abreast of regeneration requirements on current cut-overs, with the depressing picture further aggravated as a result of the wholesale movement into mechanized logging, suggests that, unless we are provided with incentives in the tax field or in the form of fixed rents, unless we can come up with cheaper and more effective regeneration techniques and unless we can minimize losses by improved protection, we cannot expect to make much impression. As far as the forest industrialist is concerned, as well as the Canadian taxpayer, the answer does not lie in abrogating the responsibility to the Crown.

Future Requirements Reforestation and Afforestation

by G. H. U. Bayly,

Deputy Minister,

Dept. of Lands and Forests,

Toronto, Ontario

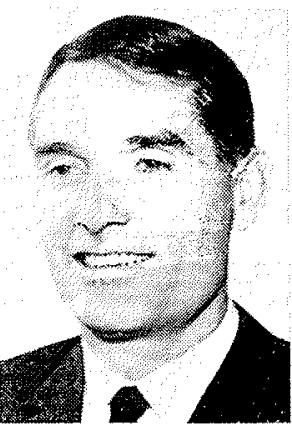

A short history of the development of afforestation and reforestation in Ontario is given as an introduction and explanation of the current situation in that province. Details of planting programs for Ontario are given perspective by a comparison with current programs in Russia.

The maintenance of full production on those lands which are available to forestry is seen as the most important future requirement. Rapid reforestation of logged areas, using the reforestation and management technique most likely to produce the quality and quantity of forest products required for the future, is vital to achieve this end. Equally important is detailed long range planning to ensure the continued availability of marketable timber when required.

It will only be possibie to fulfil estimated future requirements by a considerably expanded program of reforestation and stand improvement. From the government viewpoint, reforestation has a shortterm objective of maintaining the land production system in full operation for the products it can produce and a possibly more important long-term objective of maintaining the environmental factors of water, air and landscape in a condition suitable for people to live in.

Recent Developments and Future Trends in Reforestation in Europe with Special Emphasis on Sweden

by E. Stefansson,

Bergvik och $A B$ and Kopparfors $A B$, Soderhamn, Sweden

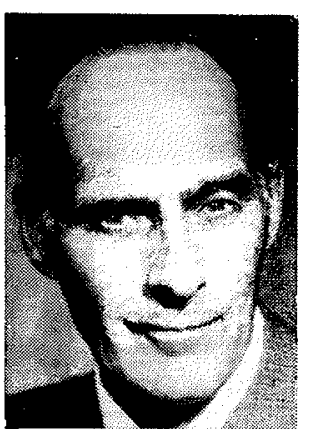

This paper is mainly concerned with progress in silvicultural practice in Sweden and the other Scandinavian countries. Reference is made to a forestry act which has been in force in Sweden since the beginning of the century and which has led to an overemphasis on the thinning of older crops in preference to final felling. At the same time labour shortages and other factors have caused a neglect of thinning in younger crops.

The small farm-forest units which are common 
in Scandinavia are now seen as a special problem in achieving rationalization of forest management. Co-operation to achieve larger management units is considered important.

Although increasing emphasis is being placed on artificial regeneration, some $50 \%$ of Swedish forests are still being regenerated by means of seed trees. In future, intensive methods of artificial regeneration are expected to be concentrated in forests with a high productive potential. The availability of better quality planting stock has also made it possible to plant smaller numbers of trees per acre and still achieve satisfactory results.

Prescribed burning is no longer considered advantageous except in areas of thick humus accumulation in Northern Sweden and to dispose of logging waste. Extensive trials are also being carried out with new types of ploughs and planting machines.

\section{Mechanization, Its Place in Reforestation}

by J. D. Scott,

Dept. of Lands and Forests, Downsview, Ontario

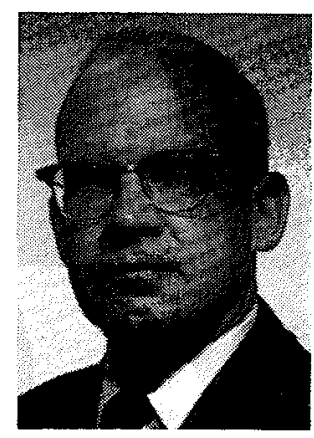

Steadily rising labour costs for reforestation purposes are making it necessary to mechanize as rapidly as possible.

Up to the present time, most of the equipment used in tree nurseries for scarification and tree planting has been designed for other fields, such as agriculture, road construction and, more recently, logging. Although this equipment has worked quite satisfactorily, there is an increasing awareness of the need for units specially designed for reforestation purposes. This applies to the broad field of reforestation and in particular to site and seedbed preparation and to planting and direct seeding. The recent developments and future trends in the mechanization and automation of equipment for site preparation and reforestation are discussed.

Fertilizers, their Role in Reforestation

by H. S. D. Swan,

Pulp and Paper Research Institute of Conada, Pointe Claire, P.Q.

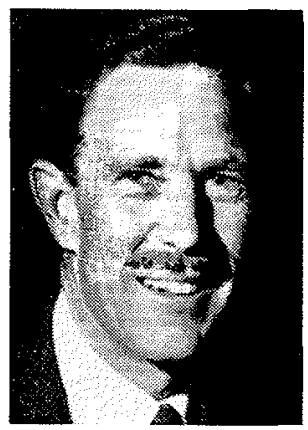

A distinction is drawn between naturally and artificially regenerated stands; the case for the use of fertilizers is stronger with respect to the latter. The role of fertilizers in seed orchards, forest nurseries, young plantations and semi-mature stands is dis- cussed. It is suggested that their use in orchards and nurseries is now, or should be, standard practice. Their use in young and semi-mature stands is governed by economics, i.e., chiefly by the value placed upon wood on the stump in any particular situation and by the cost of the fertilizer treatment. Fertilizers should not be used unless there is reason to believe that the fertilizer-grown wood will be less expensive than wood from any other alternative source of supply. A caution is given with respect to (a) the uncritical adoption of the hypothesis that only nitrogen need be applied (b) attempts to use the airplane as a research tool in forest fertilization studies. Because of its inherent imprecision as an applicator of fertilizer the airplane is considered to have but limited value during the experimental phase of a forest fertilization project. The key to success in forest fertilization is correct diagnosis which may be achieved by study of visual symptoms and by means of soil and foliar analyses. Fertilizers would appear to have an important role to play in the more intensive forestry of tomorrow. They are not a panacea and they will not solve all our forest productivity problems. Properly used in appropriate situations they can yield both biological and financial advantages.

The Role of Tree Breeding and Other Tree Improvement Practices in Reforestation

by A. L. Orr-Ewing

Reseorch Division,

B.C. Forest Service, Victoria, B.C.

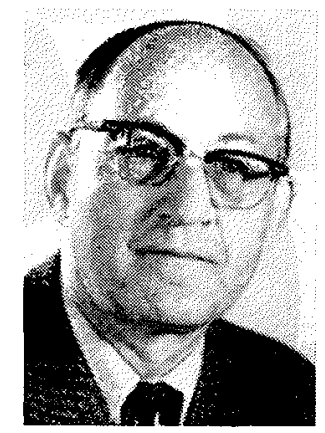

The tree breeding program with Douglas-fir which was initiated by the British Columbia Forest Service in 1952, is briefly described, together with some of the technica! problems that have already been encountered. On the basis of past experience and with continued research, the possibilities of the genetic improvement of this species are most promising.

Nursery Practices, New Developments and Future Trends

by K. A. Armson

Foculty of Forestry, University of Toranto

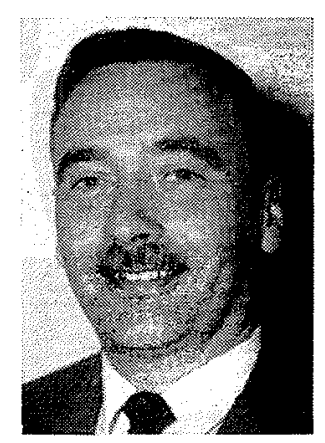

A brief review of the development of forest nurseries is made and compared with the development of methods and techniques in allied fields in agriculture.

New developments and future trends are considered primarily to consist of rapid developments in the mechanization of many of the nursery practices 
presently being carried out and a sophistication and greater emphasis on the type and quality of nursery stock produced.

The combination of conventional nursery stock, with container stock production will be common in the next decade or so.

\section{Hardwood Management in Canada}

by J. M. Jarvis,

Dept. of Forestry and

Rural Development,

St. John's, Newfoundland

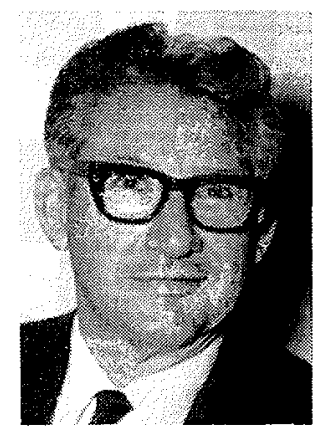

Canada's hardwood forests and present management procedures are briefly described. It is suggested that because of rapidly increasing technology every effort should be made to utilize our present mature forests as quickly as markets will permit so that economic benefits will not be lost. As demand for economical wood increases it is suggested that Canadian hardwoods will become more and more important to the industry. The most promising future for Canadian hardwoods will likely be for the production of fibre and it is quite probable that some species will be suitable for economical management on very short rotations. Although some information is available already much more knowledge is required to provide a sound biological base for the development of management procedures for whatever products may be desired in the future.

\section{Forest Insect Problems Associated with Reforest- ation}

by W. A. Reeks

Dept. of Forestry and

Rural Development, Ottawa, Ontario
Forest Disease Problems Associated with Reforestation

by R. J. Bourchier

Dept, of Forestry and

Rural Development,

Fredericton, N.B.

Forestry practices are moving toward those of agriculture. The phrase "tree-farm" is a reflection of this trend. Intensive agriculture uses plant breeding programs, fertilizers, chemical pest control methods, cultural pest control methods and complex harvesting machinery. These practices are used in a monoculture, that is, one crop per field or even per farm. The parallel with forestry developments is obvious.

The forest pathologist sees risks and benefits in this trend toward man-made forests. The uniform stand conditions provide excellent opportunities for disease spread and the stands seem to be more vulnerable to killer diseases such as root rots and stem cankers. Natural stands tend to be more heterogeneous and present a less uniformly vulnerable target to disease organisms. On the benefit side, however, man-made forests provide opportunities to use disease-resistant stock and generally are operated on shorter rotations, thus lessening the period of a tree's exposure to disease attack young trees are healthier trees.

The high dollar investment and high expected yield will necessitate more intensive disease control practices. Agriculturalists have learned some important facts concerning disease control under intensive management. For example, plant breeding for disease resistance has turned out to be a continuous process and the breeder has learned not to rely on a narrow genetic base for prolonged protection. This and other lessons from agriculture concerning soil fertilization, chemical pest control and intensive soil management should receive careful study by foresters planning new forests for old.

About 50 insect species of conifers have been reported in Canada one or more times as being destructive to nurseries, plantations, or seed crops. Innumerable other species in planted coniferous forests cause little or no damage. Reasons why we have so many insect problems in these forests are at least partially explained on the basis of available breeding material; forest site; spatial distribution, density and diversity of planted tree species; and origin of pest species. It is further suggested that problems are not static and may change in the near future because of other influences allied to new planting or cultural techniques and to the accidental introduction of exotic pest species not presently found in our country.
Mammals and the Forests of the Future

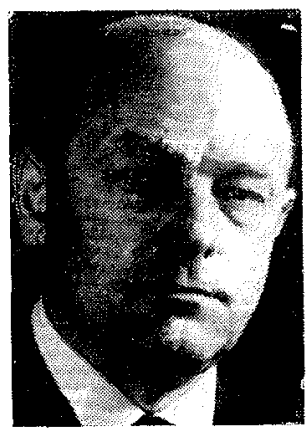

Dept. of Zoology,

University of Toronto

The interrelationships and interdependencies of the flora and fauna of future forests are considered in the light of present knowledge of the way animals influence forests and forest conditions influence animal populations.

To give perspective, the paper is introduced by a discussion of apparent and real aspects of the dam- 
age caused by browsing by deer and moose and by eating of seeds by rodents. A discussion of the importance of forestry operations, including logging and regeneration programs, to big-game populations is also included.

One of the conclusions drawn is that one of the most important influences of animals will be indirect; the result of forest operations being required to modify practices so that forest land will produce a high-value crop of wildlife for recreational purposes, as well as a valuable crop of trees.

\section{Land Classification for Plantations}

by J. R. M. Williams

Dept. of Lands and Forests, Richmond Hill, Ontario

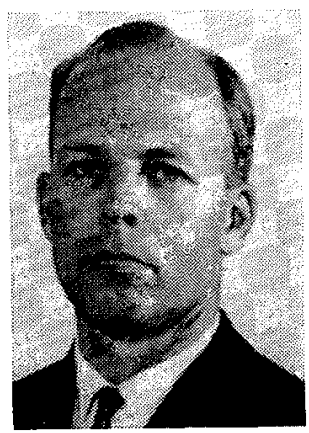

A site classification and evaluation system developed in Ontario is a practical comprehensive and necessary tool for all aspects of forest management decisions including plantation planning. It is based on scales of features of climate and landform that are significant to the capacity of the site to produce a forest crop. Positions on the various scales are determined using criteria that are observable by the forester or technician. Satisfactory tentative classification and evaluation may be made with a minimum of measured data; these may be refined as various kinds of measurements become available.

\section{Control of Competition in Plantations}

by R. F. Sutton

Dept. of Forestry and

Rural Development,

Sault Ste. Marie, Ontario

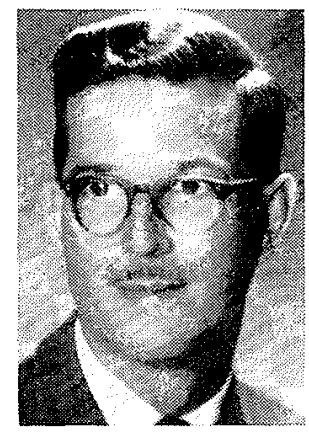

Herbicides will play important roles in that forthcoming intensification of silviculture which must inevitably accompany attempts to supply forest products to a world population whose demands have tripled in 20 years.

Herbicides are not used just to kill vegetation: they are used to divert resources from weed into crop species. Crop response, however, may be greater to the flush of fertility released from killed weeds than to reduced competition per se. The several herbicidal selectivities and many herbicides and formulations constitute a silvicultural tool of great power and versatility.

Classic situations calling for treatment in forest plantations are (a) grass sod and non-woody competition during the early years of establishment, (b) shrubby competition, and (c) overstorey competi- tion. Another case, characterized by high intra-specific competition, may be recognized. Various combinations of contact and soil sterilant herbicides are effective against grasses and other non-woody weeds, but aerial applications are unpractical. Brush may be controlled from the ground or from the air. Typical results of specific herbicide treatments are described.

Effects of Prescribed Burning on Nutrient Status of Forest Soils and Seedling Growth

by J. Baker

Dept. of Forestry and

Rural Development,

Victoria, B.C.

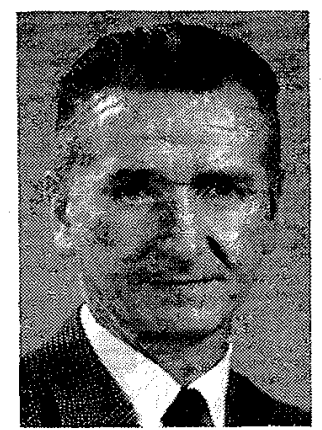

An evaluation of the effects of burning on soil properties and seedling growth was carried out. The immediate effects of burning are confined to the soil surface; however, by leaching, changes throughout the soil profile subsequently occur. Immediate modifications, which persist for a considerable time, include: increased soil $\mathrm{pH}$, extractable cations, and, in some cases, cation exchange capacity. Other changes observed are decreased organic carbon percentages and a narrowed $\mathrm{C} / \mathrm{N}$ ratio. Changes that occur immediately but persist for a shorter period are increases in both water soluble cations and anions. No significant modifications were observed in physical properties of permeability, bulk density, and mechanical composition as a result of burning. Field moisture fluctuated more frequently and rapidly on burned than on unburned soils.

Seedling growth, under controlled conditions, was much superior on undisturbed soil cores from unburned areas, than on cores from lightly or heavily burned areas. Scarification improved the growth of seedlings on burned samples. Indications are that soil $\mathrm{pH}$, particularly of the surface, governs to a large degree, the growth performance of seedlings.

The Use of Peatlands in Forestry and Agriculture

by H. W. R. Chancey

Deportment of Agriculture and Resources Newfoundland

Suitability of peatland for agriculture and forest appears to differ somewhat. Forest is a long term, relatively low-value crop; expenditures on fertilizer must be kept at a minimum. Thus it is desirable to obtain bogs relatively high in nutrients and fed by mineral-rich water. On the other hand bogs selected for agriculture are not so critical in this respect, but should preferably present a uniform surface free from impediment in large, arable blocks.

For either purpose the land must be drainable. Drainage for agriculture can be put into two cate- 
gories: (1) Permanent sod requires a ditch spacing of 75 feet to provide firm support for half-tracked tractors and haying machinery. Mole drainage can be used as a cheap supplement, diagonal to ditches. (2) Row crops or annual field crops cultivated each year require a spacing of 25 feet to support machinery on the broken surface. The narrow spacing requires covering the ditches and ridges to provide extra drainage for row-crops can be laid on the diagonal to the covered ditches.

For forestry purposes a wider, more stable ditch to last the tree growth period must be provided, and spacing of $85-110$ feet has been suggested by Heikurainen. The 1 foot planting furrows spaced every $12-13$ feet also supply supplementary drainage.

The peats investigated for agriculture are acid ( $\mathrm{pH} 3.5$ ) and contain practically no available nitrogen or phosphorus (to agricultural crops) in the virgin state and only low to medium levels of potassium. Initial requirements call for 3 tons of limestone, plus $50 \mathrm{lbs}$. of $\mathrm{N}, 100 \mathrm{lbs} . \mathrm{P}_{2} \mathrm{O}_{5}$ and $100 \mathrm{lbs}$. $\mathrm{K}_{2} \mathrm{O}$ per acre for establishing a grass-legume mixture. For yearly maintenance of high legume swards, nitrogen and phosphorus may be halved, but potassium should be increased by one half. Where grass predominates the yearly nitrogen should be doubled to $100 \mathrm{lbs}$. per acre and under some conditions somewhat more may be needed to achieve a goal of 3 tons of dry matter per acre.

The Economics of Land Use in Relation to Reforestation

by D. V. Love

Faculty of Forestry, University of Toronto

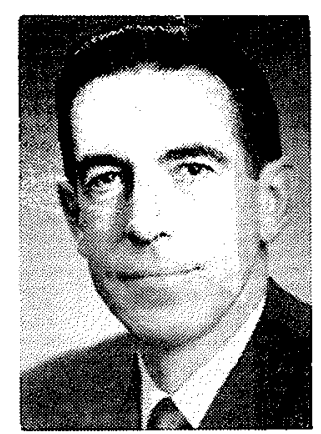

The economics of land use is a study of land use alternatives for providing guidance to the authority responsible in the ailocation of land to competing uses. The objective of economic assessment is to rank alternative uses in order of their net contribution to the interests of the authority. Conventional means of determining "net contribution" are well understood by foresters. However, when social interests are predominant, valuation may take the form of a benefit-cost analysis. Valuations based on unmodified commercial methods as a basis for land use decisions are becoming of decreasing use as the pressure for land increases, and thus social implications related to land use are given prominence.

Valuation for reforestation usually emphasizes the commercial aspects of timber utilization and has a low component of recognized externalities. Other land uses which might conflict with reforestation usually have a low commercial component in the valuation and are high in externalities. Thus in the study of the economics of land use, a conflict may develop in which a commercial value is pitted against intangible values based on externalities. If realistic decisions in forest land allocation are to be made, the external economics of reforestation must be assessed and given greater recognition. At the same time increasing efforts should be made to attach "real" values to the external economics of conflicting land uses.

Old Forests Into New: The Hydrologic Consequences

by W. W. Jeffrey

Foculty of Forestry,

University of British Columbio

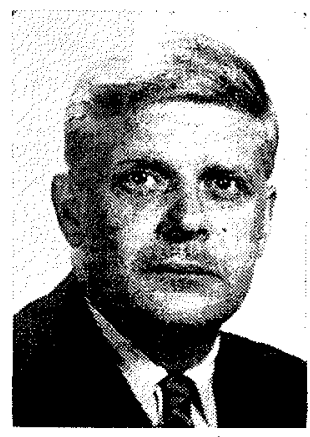

The process of transforming old forests into new has a well-recognized capacity to effect dramatic changes in the timber resource. Its impacts upon other resources; for instance, fishery, wildlife, water and recreation are less well understood and accepted. Frequently these influences are totally ignored in management. The harvesting of forest stands can affect total basin water yield, flooding, pattern of flow delivery, sediment production and chemical water quality. Effects may be either beneficial or detrimental to society as a whole. Future timber production may be affected through such mechanisms as loss of productive soil from erosion, and changes ir water table, leading to paludification. The integration of water management and timber management poses severe managerial problems; it suggests a need for modification of prevalent administrative practices; and it has a major pertinence to systems of land tenure.

\section{Multiple Use Aspects:}

Recreational Implications

by Lloyd Brooks

National and Historic

Porks Bronch,

Department of Indion Affoirs

and Northern Development,

Ottowa, Ontario.

Throughout much of Canada's accessible forest land a more systematic approach to multiple use than has been apparent in the past must be forthcoming.

By far the most dynamic and fast-growing demands on our forest resources in the last few decades are those related to outdoor recreation. Canada's National Parks are expected to receive at least five times their present visitation by the year 2000 .

The forestry profession is now showing signs of developing a consciousness and receptivity for the special environmental requirements of the recreationist in forest lands. Unfortunately, however, coordinated national direction of outdoor recreation is lacking in Canada to-day.

The Canadian Institute of Forestry is urged to broaden its horizons, to look at the forests not just as sources of wood fibre, but in a true light, as sources of a great variety of wealth, materialistic and aesthetic. 
The South Saskatchewan River Project - A Case Study of Multiple Use by W. R. Parks

by W. R. Parks

Deputy Minister

Dept. of Natural Resources Regina, Saskatchewan

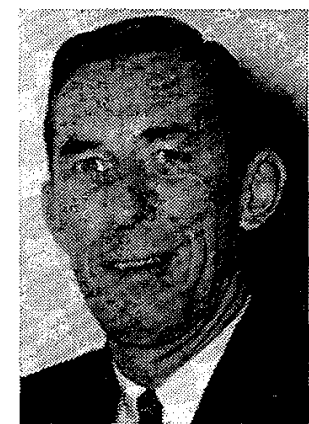

The concept of a control structure on the South Saskatchewan River originated in the 1850's when Captain Palliser and Professor Hind explored the Saskatchewan and Assiniboine Valleys. A gigantic dam across the South Saskatchewan River is today a reality.

In 1958 a formal agreement was signed between Canada and Saskatchewan to commence construction, and in 1967 the Main or Gardiner Dam and the smaller Qu'Appelle Valley Dam were officially opened. The earth-filled Gardiner Dam is approximately 3 miles long, rising 210 feet above the river bed with a base one mile side and is the largest of its kind in Canada. The reservoir, named Lake Diefenbaker, covers 109,600 acres, has a total storage capacity of 8 million acre feet and a shore line of 475 miles. The depth of water at the Main Dam is about 190 feet.

The multiple-use aspects of the project include power development, assured municipal and industrial water supplies, irrigation, and outdoor recreation. Development of 3 provincial parks and 4 cottage subdivisions is underway or planned.

Over the last 6 years nearly 1,500,000 trees of various species have been planted, some of which are now 15 to 20 feet in height. Lake Diefenbaker has an excellent sport fishery potential, unlimited boating opportunities and will provide the nimrods an entirely new hunting area for the harvesting of thousands of waterfowl.

\title{
CANADIAN FORESTRY EDUCATION STUDY
}

\author{
STATEMENT OF REVENUE \& \\ EXPENDITURES AS OF SEPTEMBER '68
}

Revenue
Donations
Exchange
Interest

Expenditures

Director's Honorarium

Less - Federal Income Tax

Director's Travel Expense

Operating Cost

Legal Fees

Printing

Postage

Translation

Office Expense

Bank Charges

Exchange (Cnd. to U.S.)

Paid to Receiver General

Total Expenditure

Cash on Hand in Bank

C.I.F.

Ontario Professional Foresters Assn.

Total additionally available if required

$$
\begin{array}{r}
33.175 .00 \\
802.00 \\
755.53 \\
\hline \$ 34,732.53
\end{array}
$$

$19,337.50$

67.40

456.93

420.66

20.00

$1,517.54$

$2,482.53$

4.15

$2,043.33$

$2,300.83$

$\$ 29.781 .17$

$4,951.36$

$10,000.00$

$2,000,00$

$12,000.00$ 